\title{
COMENTARIO
}

\section{Del hecho al dicho}

\author{
Marta Renza \\ Instituto Nacional de Salud, Bogotá, D.C., Colombia.
}

“... lugar de una posible mentira, los lenguajes y la escritura
son también la única garantía de verdad que nos queda”.

Umberto Eco

La reflexión que alienta este breve comentario me surgió en el curso de las tareas de revisión de estilo que son parte de mi compromiso en el Comité Editorial de Biomédica. Al repasar los textos de los manuscritos ya aceptados para publicación, con el fin de corregir posibles errores de gramática, sintaxis o de tipo idiomático, me preguntaba cuán extendida estaría la costumbre de utilizar las palabras sin rigor, con un desgreño a veces inimaginable, entre círculos ajenos a la comunidad científica, si en documentos forjados en el molde férreo del método científico que, en principio pondría barreras 'naturales' a tales inconsistencias, se encuentra con tanta frecuencia un uso del lenguaje que no permite expresar con claridad el contenido que se quiere comunicar.

Los seres humanos somos criaturas de lenguaje. La palabra es nuestro rasgo evolutivo particular. A través de ella y en ella establecemos nuestra propia ontología y tejemos los lazos que permiten nuestra relación con los otros y con nuestro propio ser $(1,2)$. Ello, naturalmente, nos hace a la vez amos y esclavos de su infinita variedad y de la multiplicidad de sentidos de los cuales la palabra es vector. Cuando hablamos nunca decimos sólo lo que en un primer nivel de comprensión creemos estar diciendo; siempre hay, debajo de ese plano inicial y patente, otras connotaciones que apuntan al enjambre de significantes culturales y psíquicos que nos constituyen (3).

Afortunada o infortunadamente, es difícil establecerlo, no podemos abstraernos de esa

Correspondencia:

mrenza@hemagogus.ins.gov.co

Recibido: 09/05/02; aceptado: 23/05/02 característica de desplazamiento inagotable de sentidos (4) propia del instrumento más valioso y más inquietante con que contamos como especie. Sin embargo, cuando nos abocamos a plasmar en forma escrita el producto de nuestra actividad intelectual, sobre todo en campos que, por su propia naturaleza, exigen eliminar en lo posible la ambigüedad, se impone la adopción de una postura profesional de mínima seriedad y consecuencia, una actitud que no dudo en asimilar con la de comportamiento ético: si nuestro convencimiento es que el contenido que queremos verter es útil y valioso, nuestro deber es comunicarlo de la manera más consistente y objetiva posible. Para hacerlo contamos con el instrumento del lenguaje, que debe ser tratado con el mismo rigor y aspiración de exactitud que si se tratara de un calibrador, un espectrofotómetro o una prueba de ELISA, afirmación que puede parecer un tanto radical si atendemos a lo que anoté más arriba sobre la increíble capacidad de la palabra de conferir multiplicidad de sentidos simultáneamente, pero que debe asumirse como horizonte ideal a alcanzar. No hacerlo, en mi opinión, sería entregarnos derrotados ante la creencia de que es prácticamente imposible expresar nuestras ideas, nuestras dudas y nuestras certezas con la suficiente presición y coherencia.

Desde un prisma apocalíptico, la historia de la humanidad podría verse como la historia de nuestros desencuentros en la palabra, de nuestra imposibilidad de tejer diálogos inteligentes, racionales y razonables con nuestros congéneres, lo que sería fácilmente demostrable sólo con citar tres o cuatro de las grandes guerras que marcan nuestra estadía en este planeta. Pero entregarnos a ese designio como a un destino ineludible sería abocarnos sencillamente a la muerte y, para fortuna nuestra, también es posible citar ejemplos 
alentadores de nuestra capacidad de llegar a entendimientos mínimos y productivos, desde los diálogos de Sócrates y sus discípulos, hasta la aspiración que alienta la creación de foros mundiales en los cuales, al menos en principio, el objetivo es establecer un intercambio de ideas guiado, aunque sea nominalmente, por la razón.

Esto es aún más cierto en el campo de las así llamadas ciencias naturales, cuando éstas, como lo anota Kuhn, han alcanzado un grado de madurez consolidado a través del consenso y hoy por hoy constituyen, según Steiner, el ámbito de vanguardia y el que jalona más creativamente el conocimiento $(5,6)$, ciencias cuyo principio rector, cernido por el método que rige su acción, pasa por asegurar un territorio en el que la presición de la forma pueda dar cuenta cabal de los hallazgos y los hechos a los cuales se llega a través de la comprobación experimental. Es cierto que existen campos de la ciencia que cuentan con un lenguaje de fórmulas, ecuaciones y matemas que eliminan de manera contundente el 'ruido' propio de otras formas de expresión y que, tal vez, las ciencias biomédicas, no obstante su avance en la consecución de lenguajes que responden con la precisión necesaria a sus características inherentes, se encuentran en un cruce en el que el uso del lenguaje común tiene todavía un peso considerable (7). Por ello, quienes trabajan en este campo deben realizar un esfuerzo mayor al de un matemático o un físico, a quienes la fórmula y su alto contenido de abstracción evitan, hasta cierto punto, dolores de cabeza (8). Los biólogos, entomólogos y epidemiólogos, los médicos, microbiólogos, parasitólogos y virólogos, deben combinar adecuadamente los vocablos y giros idiomáticos acuñados por su quehacer, y aceptados como correctos, y un uso apropiado de las reglas de la lengua que los nutre.

Asimilaba arriba la seriedad profesional comprometida en el empeño de expresarse claramente con una postura ética. Esta dimensión ética del tema puede no parecer obvia en una primera aproximación, pero la utilización descuidada del lenguaje que nos sirve para darle forma al producto del trabajo intelectual puede reflejar, en el fondo, el mismo descuido en el diseño de la investigación y sus objetivos, en la escogencia de los métodos y los materiales, en el planteamiento de los resultados y las conclusiones que ellos permiten, lo cual, naturalmente, cuestiona la ética profesional del investigador. La experiencia que yo y mis colegas del Comité Editorial hemos tenido me permite afirmar que así ocurre en una apreciable cantidad de casos. Cuando se comienza la lectura de un artículo y hay que luchar contra un mar recio de sustantivos convertidos en verbos a la brava, como 'alicuotar' o 'autoclavar', y de otros barbarismos semejantes, es muy difícil apreciar el verdadero alcance del contenido del proceso, supuestamente metódico, que se siguió para arribar a ciertos resultados. Los recursos que hemos anotado bien pueden convertirse en hallazgos luminosos en manos de poetas geniales, pero quien trabaja en el campo de la investigación científica asume el compromiso de divulgar el producto de su actividad de la manera más precisa posible y es su deber afinar al máximo el vehículo que utiliza para hacerlo, la lengua, la cual obedece a reglas y normas, que si bien se transforman, pues la lengua es un organismo vivo $(1,5,9)$, son necesarias para hacer inteligible lo que deseamos comunicar.

No se trata de caer en una posición fundamentalista con respecto a la corrección en el uso de la lengua: en un mundo en el que el inglés se ha convertido en lingua franca y en el que el avance incontenible de la ciencia, especialmente en el campo de la biomedicina, nos enfrenta todos los días a tecnologías y logros a los que sencillamente hay que bautizar con nuevos nombres, sería inconveniente negarse a recurrir a la ductilidad de nuestra lengua para encontrar en ella los términos que puedan nombrar realidades hasta ayer inéditas. Instituciones tan celosas de su tarea de salvaguardar la pureza de la lengua como la Real Academia comenzaron hace tiempo a aceptar vocablos provenientes de otros universos culturales, cuya negación sería simple ceguera $(7,9)$. Sin embargo, dicha flexibilidad debe darse en el marco de las coordenadas que la lengua ha establecido a lo largo de siglos para hacerse inteligible.

Como sucede con el manejo de cualquier instrumento por sencillo que sea, únicamente la 
práctica continua asegura un buen desempeño en su manipulación. En el caso del lenguaje, la práctica se centra en la disciplina de leer y escribir con frecuencia. Verter por escrito lo que el trabajo de investigación entrega a manera de nueva información es la mejor forma de perfeccionar el uso de la herramienta con que contamos para hacerlo. Si como sucede con los manuscritos que los profesionales e investigadores científicos someten ante los medios de divulgación de su campo, éstos pasan por el proceso riguroso de la evaluación por pares y por la mirada avizora de comités editoriales responsables, cuya tarea es velar por la calidad del contenido y la forma de los artículos que publican, los autores tendrán, además, la ventaja de contar con un cuerpo de observaciones que les permitirán mejorar sustancialmente, no sólo la esencia de lo que plantean en sus documentos, sino también la manera en que lo hacen.

Así, pues, la costumbre de escribir frecuentemente sobre el desarrollo de sus investigaciones y de tomar nota atenta de las observaciones que reciben de sus pares, permite a quienes se dedican a la investigación clínica, epidemiológica o básica avanzar en el camino de lograr resultados y de aprender a presentarlos con la precisión y la claridad que merecen sus colegas y los eventuales lectores legos que se acerquen a sus escritos. No hacerlo denotaría un cierto desprecio por los destinatarios de sus comunicaciones y un buen grado de estulticia, ya que un estudio podrá ser brillante, pero si el informe que da cuenta de sus procedimientos y conclusiones es ilegible poco se habrá logrado.
La actitud crítica y autocrítica, insumo y motor fundamental del método científico, constituye el mejor terreno para que los investigadores puedan aplicar ese mismo rasero a su ejercicio de consignar por escrito el producto de su trabajo.

Nos gustaría pensar, como editores de Biomédica, que el proceso de evaluación y de revisión cuidadosa del contenido y la forma de los documentos que se someten a su consideración contribuye a la formación de investigadores capaces de exponer en la escritura, con rigor y precisión, los valiosos resultados de su trabajo.

\section{Referencias}

1. Schaff A. Lenguaje y conocimiento. Segunda edición. México, D.F.: Grijalbo; 1975. p.244-65.

2. Foucault M. Las palabras y las cosas. Primera edición. Barcelona: Planeta Agostini; 1985. p.158-9.

3. Habermas J. Teoría de la acción comunicativa. I. Racionalidad de la acción y racionalización social. Primera edición. Madrid: Taurus; 1987. p.392.

4. Eco U. Tratado de semiótica general. Segunda edición. Barcelona: Editorial Lumen; 1981. p.133-8.

5. Kuhn TS. La tensión esencial. Estudios selectos sobre la tradición y el cambio en el ámbito de la ciencia. Segunda reimpresión. México: Fondo de Cultura Económica; 1996. p.248-62.

6. Steiner G. Lenguaje y silencio. Primera edición en México. México: Gedisa Editorial; 1990. p.36-7.

7. Ordóñez A. Algunos barbarismos del lenguaje médico. Med Clin (Barc) 1990;94:381-3.

8. Steiner G. En el castillo de Barba Azul. Primera edición. Barcelona: Gedisa Editorial; 1991. p.160.

9. Dauzat A. La vida del lenguaje. Primera edición. Buenos Aires: El Ateneo; 1946. p.108. 